\title{
KARAKTER DAN NILAI MORAL DALAM FILM THE PATRIOT KARYA ROLAND EMMERICH
}

\author{
Okki Hafnan \\ Postgraduate Faculty, English Language Program, Universitas Indraprasta PGRI \\ SMAN 1Cempaka Purwakarta \\ e-mail: oqhfnan@gmail.com
}

\begin{abstract}
The paper aims to analyze the problem as follows: 1) how the characters in the film and 2) how the moral values contained in Roland Emmerich's film The Patriot. The research method used is qualitative, with primary data sources taken from the film and secondary literature outside of the film. The data collection technique used is the documentation of Creswell. Documentation is a method used in scientific research to collect data using documents or lists of evidence and data analysis techniques used based on the Moleong theory. The character theory used is Russell's theory, while for moral values in the film, the writer uses Setyosih's theory. The results showed that; as; 1) the characters are divided into three, namely dominating characters are the protagonist $(48 \%)$, antagonist (28\%), and foil (24\%). 2) moral values are divided into 6, namely; tolerance (13\%), fairness $(9.09 \%)$, trust $(18.18 \%)$, kindness $(32.81 \%)$, honesty $(4.54 \%)$, and responsibility $(22.72 \%)$. This research is good for school and public education.
\end{abstract}

Keywords: characters, moral values, movie, content analysis

\section{Pendahuluan}

Kajian film dengan sastra dan bahasa memiliki kaitan yang tak terelakkan baik untuk menyampaikan pesan atau untuk memberi petunjuk kepada kelompok-kelompok tertentu dan berkomunikasi satu dengan yang lainnya. Pernyataan di atas ini sesuai dengan apa yang telah disampaikan oleh Effendy (1986 : 194) film merupakan media komunikasi yang bersifat audio visual untuk menyampaikan suatu pesan kepada sekelompok orang yang berkumpul di tempat tertentu. Film sebagai cabang seni yang memiliki pengaruh kuat terhadap pertubuhan jiwa dan kehidupan seseorang maupun kelompok. Selain sebagai wahana yang menghibur, film juga bermanfaat sebagai media pembelajaran. Film yang dianggap baik dari segi pendidikan dan audio visual adalah film yang memiliki unsur hiburan, artistik, komunikasi dan juga amanat. Seiring dengan perkembangannya, dunia perfilman telah mengalami perubahan yang sangat besar dengan banyaknya corak-corak yang bermunculan. Secara garis besar, film bisa diklasifikasikan berdasarkan cerita, orientasi pembuatan dan berdasarkan genre.

Film sendiri merupakan gabungan dari beberapa potongan gambar yang disatukan dan dapat bergerak bebas dari scene ke scene lainnya dengan ditambahkannya suara, berwarna, dan memiliki rangkaian cerita yang dapat menarik penonton. Film sendiri dibuat dengan arahan sutradara, selain itu ada juga beberapa elemen yang turut dalam membangun sebuah film antara lain, artistik, pencahayaan, dan tentu saja pengaruh kamera juga turut berperan aktif dalam membuat film. Film dalam proses pembuatannya, memerlukan pengambilan gambar yang dinamakan shot. Shot dilakukan dengan menggunakan kamera, kamera di sini mewakili atau dapat dianalogikan sebagai mata manusia. Tentu saja, dalam pengambilan gambar ini terasa adanya keterbatasan gambar (terbatasnya sudut kamera), dengan adanya pembatasan dalam pengambilan gambar ini film dapat dikatakan sebagai seni, misalnya saja seorang kameramen, diperintah oleh sutradara untuk mengambil suatu keadaan perang dengan kondisi dalam perang tersebut seluruh orang tersebut berkumpul dititik yang sama, maka kamera harus dapat mengambil sudut yang tepat, dengan keterbatasannya yang telah disebutkan di atas, maka seharusnya kamera di tempatkan beberapa meter jauh sehingga mendapatkan sudut yang sempurna untuk mengambil objek secara keseluruhan. Kejadian tersebut juga bisa dibandingkan saat penonton bioskop ingin menonton sebuah film, ketika seseorang memesan tiket dan duduk di kursi bagian atas atau yang posisinya paling jauh dengan 


\section{INFERENCE: Journal of English Language Teaching}

Vol. 4, No. 3, December 2021 - March 2022

p-ISSN: 2615-8671

e-ISSN: 2615-868X

layar bioskop, maka memperoleh sudut berbeda yang sesuai dengan daya kemampuan mata, dan posisi tersebut sempurna apabila mendapatkan bangku di bagian tengah sehingga sejajar dengan posisi layar, namun akan berbeda ketika seseorang memperoleh tiket dan duduk dibangku terdepan, karena memiliki perspektif yang berbeda dengan orang yang duduk di atas dan jauh dari layar bioskop.

Dengan keterbatasannya tersebut film pandang sebagai seni, maka peranan sutradara sangat penting. Sutradara menduduki posisi yang tertinggi dari segi artistik, karena merupakan pemimpin pembuatan film tentang "bagaimana yang harus muncul dalam kamera dan ditonton" oleh penonton. Tanggung jawab sebagai sutradara, meliputi beberapa aspek antara lain, aspek kreatif, baik interpretatif maupun teknis, dari sebuah film. Selain mengatur laku di depan kamera dan mengarahkan aktor/artis serta dialog, sutradara juga bertugas mengontrol posisi kamera, karena posisi kamera memberikan sumbangan yang besar kepada penonton dalam memahami isi dari film tersebut, selain itu sutradara juga harus mengontrol suara dan pencahayaan juga. Film merupakan sebuah seni yang banyak bergantung pada teknologi yang melibatkan manusia. Dengan ini peranan Sutradara semakin membesar, karena seorang sutradara harus memiliki wawasan dan kreatif yang baik, karena harus mampu membuat unsur-unsur yang terpisah menjadi suatu kesatuan desain serta keutuhan. Adanya wawasan dan keterampilan sutradara yang akan memberikan cap kepada film dan mengisinya dengan roh atau jiwa serta makna sehingga menjadi seni yang dapat dinikmati oleh penikmatnya.

Kegiatan di lapangan merupakan tanggung jawab sutradara dalam melaksanakan apa yang diistilahkan dalam bahasa Prancis sebagai mise en scene. Istilah tersebut diterjemahkan bebas diartikan sebagai menata dalam adegan, atau yang lebih tepatnya pengadeganan dalam kaitan dengan fungsi kamera, Tugas ini berkaitan dengan penciptaan ruang-ruang filmis berupa jenis-jenis shot. Pengertian shot di sini merupakan dipotretnya sebuah subyek, saat tombol kamera dipijit dan dilepaskan, sebagaimana yang ditentukan dalam skenario. Setiap Shot, berhubungan dengan masalah pembingkaian, yaitu sedikit atau banyaknya subyek yang dimasukkan ke dalam bingkai lalu bingkai ini menjadi film yang memberikan batas antara dunia subjek yang ditampilkan dan dunia nyata, dan bertujuan untuk memberi makna harfiah dan makna simbolik tentang apa, siapa, dan bagaimana maksud cerita yang akan disampaikan. Sebuah Film cerita terdiri atas ratusan shot. Setiap shot dihasilkan dari sudut pandang kamera (Camera angle) terhadap aksi-aksi yang hendak direkam. Sang sutradara merupakan orang pertama yang berhak menetapkan sudut pandang kamera ini. Ada tiga faktor yang menentukan sudut pandang kamera, yaitu yang pertama adalah besar-kecil subjek, yang kedua sudut subjek, dan yang ketiga ketinggian kamera terhadap subyek.

Oleh karena itu, film telah menjadi salah satu media hiburan yang sangat terkenal di masyarakat. Hampir setiap masyarakat ingin berlomba-lomba mencitakan atau ingin bergabung dalam dunia perfilman. Di samping karena keuntungan ekonomi yang besar, dunia perfilman juga menawarkan popularitas tinggi bagi para pemain dan sutradara. Sayangnya kepopuleran itu sering kali disalah kaprahkah baik oleh orang yang berkecimpung di dalam perfilman hingga orang-orang yang menikmatinya. Berbagai fenomenafenomena aneh di masyarakat telah bermunculan dikarenakan apa yang mereka tonton di layar TV atau bioskop. Seperti contoh anak-anak yang berkelahi karena ingin menirukan adegan dalam pertandingan smackdown. Ini dikarenakan besar pengaruh televisi ke dalam kehidupan masyarakat. Semua ini diakibatkan oleh sutradara film yang tidak memikirkan aspek sosial, pendidikan. Ini adalah bukti bahwa film memiliki dampak psikologi terhadap manusia terutama anak-anak.

Itu sebabnya penonton yang baik adalah penonton yang dapat memilah tonton film bisa menjadi senjata mematikan, meski secara perlahan. Oleh mereka (bangsa) yang cerdik sekaligus jahat, film menjadi salah satu medium untuk merusak karakter. Karena film juga bisa menjadi alat propaganda politik. Sebaliknya ditangan orang baik film bisa menjadi lahan potensial untuk memajukan bangsa dari segi ekonomi, ilmu pengetahuan, dan menjadi salah satu medium baik untuk melestarikan budaya bangsa. karena itu masyarakat sebaiknya mulai memperhatikan dan menyaring apa yang menjadi tontonannya baik itu acara talkshow, sinetron, maupun film. Untuk itu masyarakat harus bisa mengambil hal-hal baik dalam sebuah film baik aspek moral, sosial, maupun budaya. Karena penonton yang baik adalah penonton bisa mengambil amanat film.

Nilai moral merupakan standar bagi manusia untuk menentukan baik buruk sebuah tindakan. melalui moral juga manusia dinilai oleh lingkungan sosialnya. Moral pertama kali diajarkan oleh orang tua melalui pendidikan sejak kecil. Setelah dewasa seorang anak masuk ke dalam lingkungan sosial seperti sekolah, daerah sekitar, hingga akhirnya tumbuh dewasa dan menilai sebuah baik buruknya sebuah perilaku. 
Selain lingkungan, anak-anak juga belanja dari apa yang mereka lihat mulai dari perilaku orang tua, teman-teman hingga film-film di TV maupun bioskop. Tayangan film sering kali menjadi media belajar anak yang sering kali dilupakan oleh orang tua. Ini disebabkan karena berbagai alasan mulai dari ketidaktahuan mengenai dampak psikologi acara TV hingga pembiaran yang dilakukan oleh kedua orang tua. Padahal apa yang anak-anak tonton kelak akan menjadi panutan mereka untuk menentukan baik buruk moral mereka dewasa nanti.

Sedangkan nilai sosial merupakan nilai(peraturan) yang dianut oleh masyarakat, mengenai apa yang baik dan buruk oleh masyarakat. Penentu baik atau buruk, pantas atau tidak akan melalui proses penimbangan dahulu. Hai ini akan sangat berpengaruh oleh budaya yang ada di lingkungan masyarakat. Maka sudah sangat wajar jika terdapat perbedaan nilai-nilai antara masyarakat satu dengan yang lainnya.

Nilai sosial dalam masyarakat bisa bersumber dari tuhan, masyarakat dan individual. Sumber nilai sosial dalam agama biasa diketahui melalui kitab suci. Kitab suci ini yang kelak menjadi pedoman masyarakat dalam berperilaku. Nilai sosial yang bersumber dari masyarakat biasanya diambil dari kesepakatan mengenai hal-hal yang dianggap baik atau luhur, lalu dijadikannya menjadi pedoman dalam berilaku. Sedangkan nilai sosial yang bersumber dari tokoh biasanya bersumber dari individu luar biasa, lalu dijadikanlah tokoh tersebut sebagai pedoman masyarakat dalam berperilaku.

Nilai-nilai sosial ini yang biasanya sering dipertanyakan saat menonton film luar negeri. Apakah film ini cocok dengan nilai sosial suatu bangsa? Apakah akan terjadi bentrokan nilai sosial di masyarakat jika pemerintah membiarkan pemutaran suatu film yang memiliki nilai-nilai sangat berlawanan dari masyarakat tertentu? Bagaimana tanggapan masyarakat saat menonton film dengan nilai-nilai berlawan dari nilai yang mereka pelajari?

Oleh karena itu, film-film yang bertebaran di masyarakat haruslah film bermutu baik dari segi amanat, kualitas pemain, cerita, hingga sutradara yang baik. Untuk mendukung semua itu diperlukanlah kerja sama dari semua pihak, mulai dari pemerintah, pelaku dunia film dan masyarakat sebagai penikmat dari industri perfilman. Di Indonesia sendiri, film merupakan hiburan yang terpopuler dan berpengaruh di kalangan masyarakat.. Begitu banyaknya karya-karya anak bangsa yang bermunculan untuk dinikmati oleh penikmat hiburan negeri ini. Ditambah lagi dengan banyaknya film-film luar negeri yang ikut meramaikan industri film Indonesia. Ini dapat dibuktikan dengan selalu habisnya tiket-tiket bioskop yang habis setiap film-film unggulan dalam negeri.

Tapi sayangnya kesempatan itu kurang dimanfaatkan oleh pelaku industri film dalam negeri. Banyak sutradara-sutradara dalam negeri yang hanya membuat film tapi lupa menyisipkan amanat, baik itu berupa nilai sosial, pendidikan, atau budaya. Kebanyakan dari mereka hanyalah mengincar popularitas dengan membuat hiburan semata tapi lupa tunggu jawab mereka ke negeri ini. Keadaan tersebut membuat perfilman Indonesia terpuruk dari segi pendidikan. Seperti contohnya muncul film-film humor yang hanya membuat orang tertawa, tapi lupa untuk memberi pelajaran-pelajaran penting untuk kehidupan masyarakat. Ini membuat keadaan di mana penonton kesulitan untuk menarik nilai-nilai atau amanat yang terkandung dalam film. Jika dibiarkan begini saja bukan tidak mungkin para sutradara-sutradara tanah air akan menjadi orang-orang yang hanya memedulikan uang tanpa memedulikan dampak yang terjadi di masyarakat.

Oleh karena itu mungkin sudah saatnya Indonesia mulai mencontoh film-film luar negeri. Bukan dalam gaya perfilman tapi dari keseriusan dalam membangun dunia perfilman seperti film "The patriot" yang dapat menaikkan semangat patriotisme para penikmat film dengan berbagai bumbu yang berasil membuat film ini menyabet berbagai penghargaan seperti penghargaan Amerika Society of Cinematographers untuk Outstanding Achievement in Cinematography in Theatrical Releases dan People's Choice Award untuk aktor film favorit. Ini merupakan bukti nyata dari keseriusan dalam pembuat film.

Film "the patriot" sendiri merupakan film yang disutradarai oleh Roland Emmerich yang menceritakan tentang seorang petani yang bernama Benyamin Martin yang nantinya akan menjadi kunci dalam kemenangan Amerika terhadap inggris. Sutradara Emmerich berhasil mengangkat film ini dengan berbagai bumbu sehingga dapat meningkatkan semangat patriotisme para penonton walaupun sayangnya ada beberapa kesalah fatal dalam pembuatan film sehingga tidak sesuai dengan sejarah Benyamin Martin.

Banyak sekali nilai moral dan nilai sosial yang bisa penonton ambil dalam film ini. Seperti adegan akhir di mana sang karakter utama( Benyamin Martin) memimpin perang untuk kemenangan Amerika atau cara cerdik Martin untuk memotong suplai makan tentara musuh dan bagaimana ia dapat memimpin temantemannya untuk melawan Inggris. Indonesia sendiri terdapat banyak kemajuan dalam dunia perfilman dengan berbagai penghargaan yang berhasil digapai oleh para pembuat film tanah air. Sayangnya film-film 


\title{
INFERENCE: Journal of English Language Teaching
}

Vol. 4, No. 3, December 2021 - March 2022

p-ISSN: 2615-8671

e-ISSN: 2615-868X

yang bertemakan patriotisme, nasionalisme, dan NKRI ini kerang mendapatkan perhatian di kalangan pembuat film dengan sedikitnya film yang bertemakan patriotisme. Itu sebabnya analisis ini dibuat untuk meningkatkan keinginan pembuat dan penikmat film untuk tidak hanya membuat atau menikmati hiburan semata tapi bisa membalut karyanya dengan nilai moral dan sosial. Oleh sebab itu analisis ini akan mengambil film "The patriot" untuk yang memiliki karakter adan nilai moral yang ada dalam cerita.

\section{Metode}

Sebelum melakukan penelitian, peneliti terlebih dahulu harus menentukan metode apa yang cocok dengan subjek yang akan dia analisis. Kesalahan dalam menentukan metode yang akan gunakan akan menyebabkan hasil penelitiannya tidak valid. Dengan kata lain, seorang peneliti harus mampu menentukan metode yang akan digunakannya dalam sebuah penelitian.

Penelitian ini adalah untuk menemukan analisis karakter dan nilai moral dari film "The Patriot" yang disutradarai oleh Roland Emmerich. Karena judul itu sendiri adalah bagian dari karya sastra, oleh karena itu, yang paling cocok digunakan dalam mencari dan menggambarkan temuan karakter dan nilai moral adalah penelitian kualitatif. Dalam penelitian ini, penulis menggunakan penelitian kualitatif. Menurut Creswell (2013: 62) menyatakan:

\begin{abstract}
Qualitative research is an inquiry approach useful for exploring and understanding a central phenomenon. To learn about this phenomenon, the inquirer asks participants broad general questions, collects the detailed views of participants in the form of words or images, and analyses the information for description and themes. From this data, the researcher interprets the meaning of the information, drawing on personal reflection and past research. The final structure of the final reports is flexible, and it displays the researcher's biases and thoughts.
\end{abstract}

Dari pernyataan di atas dapat dilihat bahwa kualitatif adalah sebuah pendekatan dalam penelitian yang berdasarkan fenomena yang dipilih oleh peneliti dan mengatasi masalah penelitian di mana variabel tidak diketahui dan memerlukan eksplorasi.

Penelitian ini menekankan pada temuan judul melalui analisis karakter dan nilai moral film. Penelitian kualitatif adalah sistem penyelidikan yang berupaya membangun deskripsi holistik, sebagian besar, naratif, untuk menginformasikan pemahaman peneliti tentang fenomena sosial atau budaya. Penelitian kualitatif dilakukan di lingkungan alami yang menggunakan kombinasi pengamatan, wawancara, dan tinjauan dokumen.

Sumber pengumpulan data yang paling umum dalam penelitian kualitatif adalah wawancara, observasi, dan tinjauan dokumen (Creswell, 2009b; Locke, Silverman, \& Spirduso, 2010; Marshall \& Rossman, 1999). Dalam penelitian ini, metode pengumpulan data yang diterapkan adalah dokumentasi (Creswell: 2009). Dokumentasi adalah metode yang digunakan dalam penelitian ilmiah untuk mengumpulkan data dengan menggunakan dokumen atau daftar bukti. Teknik dokumentasi biasa menjadi teknik paling umum dalam melakukan analisis teks.

Sebuah penelitian ilmiah harus mengikuti tahapan spesifik dan juga harus memenuhi persyaratan yang ditetapkan. Hal ini dimaksudkan agar hasil penelitian tersebut dapat dipertanggung jawabkan keabsahannya. Meski begitu dalam penulisan tesis ini, penulis harus mengikuti tahapan dan persyaratan yang diminta. Dan dalam melakukan setiap kegiatan penelitian, penulis juga mengikuti atau melakukan proses secara bertahap.

Sebelum penulis menjelaskan data, ada beberapa langkah yang harus dilakukan atau dipenuhi dalam pengumpulan data. Dalam prosedur pengumpulan data, Creswell (2007: 213) menyatakan bahwa langkah-langkah pengumpulan data meliputi, (a) menetapkan batas-batas untuk penelitian (b) mengumpulkan informasi melalui observasi dan wawancara terstruktur atau semi terstruktur, wawancara, dokumen, dan visual bahan (c) menetapkan protokol untuk merekam informasi. Ada beberapa langkah pengumpulan data, berikut:

- Identifikasi dokumen yang dipilih secara sengaja untuk dipelajari. Dalam penelitian ini, dokumen tersebut adalah dialog dalam film "The Patriot" karya Roland Emmerich 
- Menunjukkan jenis data yang dikumpulkan. Penelitian akan menghabiskan waktu yang cukup lama dalam mengumpulkan informasi dari film. Lalu, penulis mengambil naskah. Dan kemudian penulis akan pengumpulan dan membandingkan film dan naskah. Penulis juga akan mengulangi film untuk menemukan data yang relevan dan mengumpulkan data yang mencerminkan karakter dan nilai moral.

- Diskusi data. Dalam diskusi tentang teknik pengumpulan data, penulis akan jelaskan tentang data tersebut dan sertakan mengadakan argumen mengenai kekuatan dan kelemahan masing-masing opini. Data yang terkumpul kemudian akan diklasifikasikan sesuai dengan tujuan penelitian.

\section{Hasil dan Diskusi}

\section{a. Karakter dalam film "The Patriot"}

Penelitian ini adalah untuk menemukan analisis karakter dan nilai moral dari film "The Patriot" yang disutradarai oleh Roland Emmerich. Karena judul itu sendiri adalah bagian dari karya sastra, oleh karena itu, yang paling cocok digunakan dalam mencari dan menggambarkan temuan karakter dan nilai moral adalah penelitian kualitatif. Dalam penelitian ini, penulis menggunakan penelitian kualitatif. Russel (2009, p.1) menyatakan, bahwa ada tiga jenis karakter. Mereka:

(1) Protagonis

Protagonis adalah tokoh sentral yang dengannya kita biasanya menekankan atau mengidentifikasi. Tokoh protagonis yang ditemukan penulis dalam film The Patriot adalah Benjamin Martin sebagai penggerak pasukan milisi

(2) Antagonis

Antagonis adalah tokoh yang menentang protagonis dan menciptakan konflik. Tokoh-tokoh antagonis yang ditemukan penulis dalam film "The Patriot" adalah Kolonel William Tavington dan Jenderal Charles Cornwallis

(3) Foil

Foil adalah sosok yang sifat kepribadiannya adalah kebalikan dari karakter utama. Ini adalah karakter pendukung dan biasanya dibuat untuk menyinari protagonis.

b. Nilai Moral dalam Film "The Patriot"

kedua adalah tentang nilai moral. Kartu digunakan untuk menganalisis jenis nilai moral dalam film The Patriot oleh Roland Emmerich. Kartu data ini juga memiliki beberapa komponen yang dapat membantu pengguna menentukan nilai moral apa yang ingin disampaikan oleh film. Sebagaimana dinyatakan dalam bab kedua dan sesuai dengan teori yang dinyatakan oleh Setyasih, ada enam jenis nilai moral;

1) Toleransi

Toleransi adalah kesediaan untuk menerima perilaku dan kepercayaan yang berbeda satu sama lain, walaupun mungkin berbeda keyakinan atau memiliki keyakinan yang sama. Setyoasih (2015: 21) berpendapat bahwa ada rasa simpati yang sangat praktis, yang mengikuti dari gagasan fasih bahwa siapa pun bebas untuk menghargai apa pun.

2) Keadilan

Keadilan didefinisikan sebagai kualitas memperlakukan orang secara adil atau dengan cara yang benar atau masuk akal. Kita dihadapkan pada prospek adanya tindakan dan sistem sosial yang "benar" secara moral, yang, secara seimbang, tanpa merugikan kesejahteraan orang lain

3) Keyakinan

Kepercayaan adalah keadaan atau kebiasaan dalam pikiran di mana kepercayaan, kepercayaan, ditempatkan pada seseorang atau sesuatu. Keyakinan adalah sesuatu yang diyakini, pernyataan atau ucapan yang dipegang oleh para pendukung berbagai pandangan; Keyakinan akan kebenaran dari beberapa pernyataan atau ucapan dari beberapa manusia atau fenomena, terutama ketika didasarkan pada pemeriksaan atas dasar untuk menerimanya sebagai benar atau nyata.

4) Baik hati

Baik Hati adalah setara dengan apa yang telah ditawarkan atau diterima. Macam lebih sering diterapkan pada disposisi untuk simpati dan membantu. Mohon lebih menekankan ekspresi simpatik, bermanfaat, suasana hati atau impuls (orang baik dengan minat yang baik dalam masalah orang lain).Baik 


\section{INFERENCE: Journal of English Language Teaching}

Vol. 4, No. 3, December 2021 - March 2022

p-ISSN: 2615-8671

e-ISSN: 2615-868X

hati memiliki sifat simpatik: Manusiawi, penyayang. Kebaikan hati adalah kualitas atau keadaan kebaikan hati (Setyoasih, 2015: 22).

5) Kejujuran

Kejujuran adalah karakter yang dapat diperkirakan; keadilan dan kelanjutan dari perilaku atau kepatuhan terhadap fakta. Kejujuran berasal dari akal-akalan atau duplikat kebenaran, dan ketulusan

6) Tanggung jawab

bertanggung jawab adalah memiliki kontrol dan otoritas atas sesuatu atau seseorang dan menjadi tugas merawatnya atau menjaganya

\section{Pembahasan \\ a. Karakter Dalam Film "The Patriot"}

Penelitian ini adalah untuk menemukan analisis karakter dan nilai moral dari film "The Patriot" yang disutradarai oleh Roland Emmerich. Karena judul itu sendiri adalah bagian dari karya sastra, oleh karena itu, yang paling cocok digunakan dalam mencari dan menggambarkan temuan karakter dan nilai moral adalah penelitian kualitatif. Dari pernyataan di atas dapat dilihat bahwa kualitatif adalah sebuah pendekatan dalam penelitian yang berdasarkan fenomena yang dipilih oleh peneliti dan mengatasi masalah penelitian di mana variabel tidak diketahui dan memerlukan eksplorasi. Russel (2009, p.1) menyatakan, bahwa ada tiga jenis karakter. Mereka:(1) Protagonis (48\%). (2) Antagonis (28\%). (3) Foil(24\%).

\section{b. Nilai Moral dalam Film "The Patriot"}

kedua adalah tentang nilai moral. Kartu digunakan untuk menganalisis jenis nilai moral dalam film The Patriot oleh Roland Emmerich. Data ini juga memiliki beberapa komponen yang dapat membantu pengguna menentukan nilai moral apa yang ingin disampaikan oleh film. Sebagaimana dinyatakan dalam bab kedua dan sesuai dengan teori yang dinyatakan oleh Setyosih, ada enam jenis nilai moral; Toleransi $(13 \%)$, ,Keadilan $(9,09 \%)$, Keyakinan $(18,18 \%)$, Baik hati $(31,81 \%)$, Kejujuran $(4,54)$ Tanggung jawab $(22,72 \%)$

\section{Simpulan}

Film 'The Patriot' memiliki tiga jenis karakter yaitu protagonis, antagonis, dan foil. Karakter protagonis memiliki jumlah persentase $48 \%$ dan ini merupakan karakter adalah dengan jumlah dialog terbanyak. Karakter antagonis memiliki jumlah 28\%, ini berarti karakter ini memiliki jumlah dialog terbanyak setelah protagonis. Dan yang terakhir adalah karakter foil yang memiliki jumlah persentase $24 \%$. Setelah menganalisis data yang ditemukan dalam film "The Patriot" oleh Roland Emerich, penulis dapat menarik kesimpulan bahwa nilai moral yang pelayan dalam film ini adalah sebagai berikut; toleransi adalah $13 \%$, keadilan adalah $9,09 \%$, kepercayaan $18,18 \%$ dan baik hati adalah $31,81 \%$, kejujuran $4,54 \%$ dan tanggung jawab $22,72 \%$. Baik hati dan tanggung jawab adalah persentase paling tinggi dalam film ini dikarenakan, film ini menceritakan tentang tanggung jawab dan kebaikan hati sang protagonis di dalam peperangan. kebaikan yang terhadap keluarga dan orang lain. Tanggung jawab dalam melindungi keluarga dan pasukan milisi. Sangat diharapkan bagi orang yang menyaksikan film ini dapat mengerti moral yang terdapat dalam film karya Roland Emmerich.

Film The Patriot bermanfaat bagi siswa untuk mempelajari keburukan moral seperti keberanian, optimisme, kejujuran yang setia dan cinta. Siswa diharapkan untuk meniru sifat baik dari unsur nilai moral dari film ini dapat digunakan sebagai bahan pengajaran, terutama tentang sosiolinguistik dan nilai moral yang berasal dari film The Patriot, Guru juga diharapkan untuk lebih menanamkan sifat apresiasi karya kreatif maka siswa dapat membedakan apakah hal itu baik dan buruk dalam karya kreatif yang layak ditiru begitu juga sebaliknya. Film The Patriot karya Roland Emmerich sangat menarik dan mengagumkan untuk ditonton dan dianalisis. Peneliti dapat mempelajari tentang bagaimana film tersebut dikonstruksi dan pesan dari film yang akan disampaikan. Ada juga sekuel dari film ini yang dapat dianalisis yang belum dianalisis. 


\section{Daftar Rujukan}

Arnherm, R. (2003). Film as Art. California: University of California Press.

Afdilila, M. (2015). The moral values of social dialect in hamlet movie. Semarang: UIN Walisongo.

Alwi, S. (2008). Manajemen Sumber Daya Manusia $\left(2^{\text {nd }}\right.$ ed), Yogyakarta: BPFE

Aminigo, I. M. (2003).Model Essays in Moral Education. Buguma: Hanging Gardens Publishers

Aminigo, I. M. \& Nwaokugha, D. O. (2006).An Advanced Introduction to Philosophy of Education. Choba: Zelta Research Consult.

Aspin, M. (2007).Toward an Anthropological Theory of Value, The False Going of Our Own Dreams, New York: Palgrave.

Berg, B. L. (2001). Qualitative Research Method for The Social Science. London: Pearson Education Company.

Boggs, J. M. \& Petrie, D. W. (2008). The art of watching film. $7^{\text {th }}$ edition. New York: McGraw-Hill Company

Chandler, M, G. (2018). The Element of Character Frankfurt am Main: Outlook Verlag GmbH. New

York: Greenwood Press

Chase, M, E. (2005). Values in Literature. Boston, USA: Houghton Mifflin Company.

Ekpiwre, C. A. (2008). Socialization and Value Re-Orientation in the Family: Implications for

Effective Education Reforms in Nigeria. Nigerian Journal of Sociology of Education, 2 (2): 174.

Nigeria: Word press

Elizabeth, B. 2000. Moral Development, Sixth Edition. Singapore: McGraw Hill Book Company.

Gehring, W. D. (2000).Clown comedy. In W. D. Gehring (Eds.), Handbook of American film genres. New York: Greenwood Press

Hall, E, W. (2014). What is value? New York: Routledge.

Hare, R, S. (2009).The language of Morals. Oxford: Clarendon Press.

Hu, S. F. (2006). On Teaching Non-English Majors Listening and Speaking Through Videos. China

English Language Education Association Journal. Accessed on 18th of February 2017.

Hurlock, E, B. (2000). Moral Development, Third Edition. Mc, Graw: Hill Book Company.

James, S. (2014). Creating Characters. Ottawa: Writers Digest Book. T,

Johnston, E. J. Goodness, Impact of Parental Discipline Methods on The Child's Internalization of Values: A Reconceptualization of Current Points of View, Developmental Psychology, 1994, 30 : 4-19.

Zuriah, N. (2007). Pendidikan Moral dan Budi Pekerti dalam Perspektif rubahan. Jakarta: Bumi Aksara 